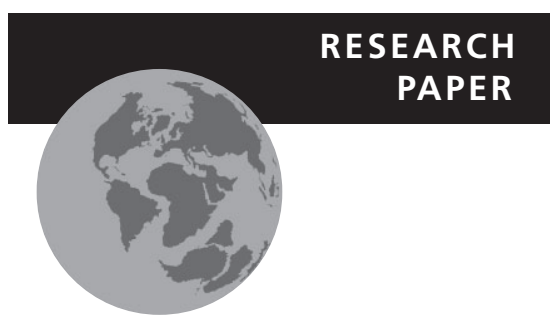

\section{Global effects of soil and climate on leaf photosynthetic traits and rates}

\author{
Vincent Maire ${ }^{1 \star \dagger}$, Ian J. Wright ${ }^{1}$, I. Colin Prentice ${ }^{1,2}$, Niels H. Batjes ${ }^{3}$, \\ Radika Bhaskar ${ }^{4}$, Peter M. van Bodegom ${ }^{5}$, Will K. Cornwell ${ }^{6,7}$, \\ David Ellsworth ${ }^{8}$, Ülo Niinemets ${ }^{9}$, Alejandro Ordonez ${ }^{10}$, Peter B. Reich ${ }^{8,11}$ and \\ Louis S. Santiago ${ }^{12,13}$
}

${ }^{1}$ Department of Biological Sciences, Macquarie University, North Ryde, NSW 2109, Australia, ${ }^{2} A X A$ Chair of Biosphere and Climate Impacts, Grand Challenges in Ecosystems and the Environment and Grantham Institute Climate Change and the Environment, Department of Life Sciences, Imperial College London, Ascot SL5 7PY, UK, ${ }^{3}$ ISRIC - World Soil Information, $6700 \mathrm{AJ}$ Wageningen, The Netherlands, ${ }^{4}$ Environmental Change Initiative, Brown University, Providence, RI, USA, ${ }^{5}$ Institute of Environmental Sciences, Leiden University, 2333 CC Leiden, The Netherlands, ${ }^{6}$ Department of Systems Ecology, Institute of Ecological Science, VU Amsterdam, 1081 HV Amsterdam, The Netherlands,

${ }^{7}$ School of Biological, Earth and Environmental Sciences, University of New South Wales, Sydney, NSW 2052, Australia, ${ }^{8}$ Hawkesbury Institute for the Environment, University of Western Sydney, Penrith, NSW 2751, Australia, ${ }^{9}$ Institute of Agricultural and Environmental Sciences, Estonian University of Life Sciences, Tartu 51014, Estonia,

${ }^{10}$ Department of Bioscience, Aarhus University, Aarhus, Denmark, ${ }^{11}$ Department of Forest Resources, University of Minnesota, St Paul, MN 55108, USA, ${ }^{12}$ Botany and Plant Sciences Department, University of California, Riverside, CA, USA, ${ }^{13}$ Smithsonian Tropical Research Institute, Panama, Panama

${ }^{*}$ Correspondence: Vincent Maire, Department of Biological Sciences, Macquarie University, North Ryde, NSW 2109, Australia. E-mail: vmaire24@gmail.com $†$ Present address: Université du Québec à Trois-Rivières, CP 500, Trois-Rivières, Québec, Canada G9A 5H7.

\section{ABSTRACT}

Aim The influence of soil properties on photosynthetic traits in higher plants is poorly quantified in comparison with that of climate. We address this situation by quantifying the unique and joint contributions to global leaf-trait variation from soils and climate.

Location Terrestrial ecosystems world-wide.

Methods Using a trait dataset comprising 1509 species from 288 sites, with climate and soil data derived from global datasets, we quantified the effects of 20 soil and 26 climate variables on light-saturated photosynthetic rate $\left(A_{\text {area }}\right)$, stomatal conductance $\left(g_{s}\right)$, leaf nitrogen and phosphorus $\left(N_{\text {area }}\right.$ and $\left.P_{\text {area }}\right)$ and specific leaf area (SLA) using mixed regression models and multivariate analyses.

Results Soil variables were stronger predictors of leaf traits than climatic variables, except for SLA. On average, $N_{\text {area }} P_{\text {area }}$ and $A_{\text {area }}$ increased and SLA decreased with increasing soil $\mathrm{pH}$ and with increasing site aridity. $g_{s}$ declined and $P_{\text {area }}$ increased with soil available $\mathrm{P}\left(P_{\text {avail }}\right)$. $N_{\text {area }}$ was unrelated to total soil $\mathrm{N}$. Joint effects of soil and climate dominated over their unique effects on $N_{\text {area }}$ and $P_{\text {area }}$, while unique effects of soils dominated for $A_{\text {area }}$ and $g_{s}$. Path analysis indicated that variation in $A_{\text {area }}$ reflected the combined independent influences of $N_{\text {area }}$ and $g_{s}$, the former promoted by high $\mathrm{pH}$ and aridity and the latter by low $P_{\text {avail. }}$.

Main conclusions Three environmental variables were key for explaining variation in leaf traits: soil $\mathrm{pH}$ and $P_{\text {avail }}$, and the climatic moisture index (the ratio of precipitation to potential evapotranspiration). Although the reliability of global soil datasets lags behind that of climate datasets, our results nonetheless provide compelling evidence that both can be jointly used in broad-scale analyses, and that effects uniquely attributable to soil properties are important determinants of leaf photosynthetic traits and rates. A significant future challenge is to better disentangle the covarying physiological, ecological and evolutionary mechanisms that underpin trait-environment relationships.

\section{Keywords}

Least-cost theory of photosynthesis, nitrogen, phosphorus, photosynthesis, plant functional traits, soil fertility, soil $\mathrm{pH}$, stomatal conductance. 


\section{INTRODUCTION}

Natural selection promotes coordination in plants between the acquisition of soil-derived resources (water and nutrients), capture of solar radiation and the uptake and fixation of $\mathrm{CO}_{2}$ from the atmosphere. The relative availability of key resources to plants varies by orders of magnitude over biogeographical gradients (e.g. Vitousek, 2004; Huston, 2012). Identifying how this variation shapes the ecological strategies and key strategy traits of plants is one of the central questions for ecology and biogeography (Westoby \& Wright, 2006).

Photosynthesis can be construed as an economic process (Givnish, 1986). A trade-off between the substitutable costs of maintaining the capacities for carboxylation $\left(V_{\mathrm{cmax}}\right)$ and transpiration was theoretically predicted and then confirmed by experimental observation along an Australian aridity gradient with annual precipitation ranging from c. 400 to $1100 \mathrm{~mm}$ (Prentice et al., 2014). From dry to wet habitats, plants maintain comparable photosynthetic rates by increasing their water use with high stomatal conductance $\left(g_{s}\right)$ while reducing investment in photosynthetic proteins resulting in low leaf $\mathrm{N}$ and $V_{\text {cmax }}$ (Wright et al., 2003). Analogously, along a gradient from nutrient-poor to nutrient-rich habitats, plants were shown to rely increasingly on high leaf $\mathrm{N}$ while reducing water use by operating at lower $g_{s}$ (Wright et al., 2001). However, along the gradient studied by Wright et al. (2001), covariation of soil texture, cation exchange capacity, organic matter content and total $\mathrm{N}$ and $\mathrm{P}$ concentrations precluded a more differentiated analysis of soil effects.

Moreover, the impact of soil on photosynthetic traits has rarely been studied at a global scale (Ordoñez et al., 2009; Ordonez \& Olff, 2013). Investigation of this relationship is challenging because climate is both a major control of photosynthetic traits (e.g. Reich \& Oleksyn, 2004) and an important driver of soil development. According to Albrecht's conceptual model (Huston, 2012), soil total exchangeable bases, soil pH, soil total $\mathrm{P}$ and $\mathrm{N}$ content and plant productivity should all decline along a gradient from intermediate to high rainfall and from young high-latitude soils to older, low-latitude well-weathered soils (Walker \& Syers, 1976). Soil fertility, sometimes defined by exchangeable base cations or soil pH (Quesada et al., 2010), might thus be expected to be inversely related to water availability, and this trade-off might be reflected in both increasing stomatal conductance and decreasing carboxylation capacity towards warm and wet climates.

However, this one-dimensional view of covariation between soils and climate is likely to be an oversimplification. Soil fertility can also be defined in several other ways. Conceptual models of long-term ecosystem development have tended to focus on the negative covariation between time trajectories of the availability of $\mathrm{P}$ and $\mathrm{N}$ in soils, with the highest productivity at intermediate $\mathrm{N}$ : P ratios (Vitousek, 2004). In such schemes $\mathrm{N}$ is assumed to be more limiting in young soils, often at higher latitudes, since it accumulates mainly via atmospheric fixation of $\mathrm{N}_{2}$ and becomes available to plants mainly via decomposition of organic matter. However, in old and deep soils, mostly at lower latitudes, $\mathrm{P}$ is provided mainly by the parent rock chemistry and its weathering rates becomes a limiting factor for plant growth (Reich \& Oleksyn, 2004; Peltzer et al., 2010). In this scheme the relative cost associated with the maintenance of carboxylation should increase at the extremities of time trajectories for soil development, either limited by soil and leaf $\mathrm{N}$ or by soil and leaf P (Niinemets et al., 1999; Reich et al., 2009; Maire et al., 2012). Finally, biogeochemical models of ecosystems have tended to adopt a narrow definition of fertility, focused on the ability of soils to release plant-available forms of nutrients from litter and soil organic matter (SOM), the decomposition of which is supposed to be mainly a function of the initial SOM and temperature (Hakkenberg et al., 2008), as well as which microorganisms are present (Fontaine et al., 2011). The implications of this scheme for photosynthetic costs are less clear. Globally, these differing concepts of soil fertility continue to exist side-by-side in the literature but, to date, none of the broad concepts has been embedded in a global, predictive framework for plant traits. Indeed, shifting and ambiguous definitions of 'fertility' may have hindered the development of such a framework. With sufficient data, however, it should be possible to tease apart the effects of the various edaphic drivers on photosynthetic traits and to separate influences of edaphic and climatic determinants of photosynthesis.

Recently, a global soil dataset with consistency, reliability and resolution approaching those available for climate has become available with SoilGrids (ISRIC, 2013), which is complementary to the ongoing update of the conventional Harmonised World Soil Database (FAO et al., 2012). These soil data can be linked with global datasets containing climate variables and plant traits, making it possible for the first time to quantify the unique contribution of soil variables to leaf traits across the range of global ecosystem types. We performed such an analysis, with the following questions.

1. How do leaf photosynthetic traits vary with different facets of soil fertility?

2. What are the most individually important soil and climate variables in terms of explaining variation in these leaf traits?

3. What proportions of leaf trait variation can be accounted for by joint effects of soils and climate, as opposed to the unique effects of soils and of climate? As climate and soil covary, the soil-climate joint effect may dominate the unique effects of climate and soil separately (Reich \& Oleksyn, 2004). As different soils are encountered in a given climatic envelope, a significant unique effect of soils may be expected.

4. Variation among species in photosynthetic rates depends both on variation in leaf $\mathrm{N}$ and in $g_{s}$. Are these two independent trait dimensions promoted by independent climate and soil dimensions?

5. Finally, what is the minimum set of environmental and trait variables needed to represent interrelationships between photosynthetic rates and associated traits?

To answer each question, a step-by-step statistical approach was followed (described below), with the ultimate aim of disentangling soil and climate effects on leaf traits and photosynthetic rates. 


\section{MATERIAL AND METHODS}

\section{Trait data}

The 'Glopnet' dataset (Wright et al., 2004) provided the starting point for the present analyses. Data on field-measured photosynthetic capacity $\left(A_{\text {area }}, \mu \mathrm{mol} \mathrm{m} \mathrm{m}^{-2} \mathrm{~s}^{-1}\right)$, stomatal conductance to water vapour $\left(g_{s}, \mathrm{mmol} \mathrm{m}^{-2} \mathrm{~s}^{-1}\right), \mathrm{N}$ and $\mathrm{P}$ per unit leaf area $\left(N_{\text {area }}\right.$ and $P_{\text {area }}, \mathrm{g} \mathrm{m}^{-2}$, respectively) and specific leaf area $\left(S L A, \mathrm{~cm}^{2} \mathrm{~g}^{-1}\right)$ were supplemented by other sets of georeferenced observations of these traits (Appendix S1 in Supporting Information). The final database (Appendices S2 \& S3, doi:10.5061/dryad.j42m7) consisted of 2400 species $\times$ site combinations including 288 sampled sites and 1509 species from 165 families. Three hundred and twenty-five species occurred at more than one site. The dataset contained a variety of growth forms (661 trees, 399 shrubs, 313 herbs, 88 grasses, 32 ferns and 16 vine species), phenologies (316 deciduous, 14 semi-deciduous and 735 evergreen species) and physiologies (i.e. $\mathrm{C}_{3}$ and $\mathrm{C}_{4}$ species, $\mathrm{N}_{2}$-fixing and non-fixing species). $A_{\text {area }}$ varied 190-fold across the dataset (from 0.34 to $65.05 \mu \mathrm{mol} \mathrm{m}{ }^{-2} \mathrm{~s}^{-1} ; n=2337$ ), $g_{\mathrm{s}}$ varied $c$. 110 -fold (from 21 to $2272 \mathrm{mmol} \mathrm{m}^{-2} \mathrm{~s}^{-1} ; n=1035$ ), $N_{\text {area }}$ and $P_{\text {area }}$ varied by c. 40 -fold (from 0.26 to $9.47 \mathrm{~g} \mathrm{~N} \mathrm{~m}^{-2} ; n=1643$ ) and 50 -fold (from 0.017 to $0.923 \mathrm{~g} \mathrm{P} \mathrm{m}^{-2} ; n=512$ ), respectively, and SLA varied c. 50 -fold (from 12.8 to $608 \mathrm{~cm}^{-2} \mathrm{~g}^{-1} ; n=1965$ ). By comparison, the 2004 Glopnet dataset had $A_{\text {area }}$ data for 825 species $\times$ site combinations and $g_{\text {s }}$ data for 500 .

\section{Environmental data}

\section{Climatic drivers}

Photosynthetically active quantum flux density, temperature, rainfall and aridity are key climatic determinants of plant processes. Twenty-six climate variables representing these aspects of climate were considered (Table S3-1 in Appendix S3). When available, mean annual temperature and precipitation data were taken from the source publications for the leaf data. Otherwise, climate data were extracted from a global, three-dimensionally interpolated $10^{\prime} \times 10^{\prime}$ data set for 1961-90 (Climatic Research Unit, CRU CL2.0; New et al., 2002). We obtained monthly and annual means of temperature, rainfall, fractional sunshine duration and relative humidity. We also considered maximum and minimum values, seasonal variability and growing-season mean values (defined alternatively based on a $0{ }^{\circ} \mathrm{C}$ and a $5{ }^{\circ} \mathrm{C}$ basis) of temperature, precipitation and sunshine duration. Next, several bioclimatic variables were calculated following Wang et al. (2014): annual global radiation, total annual incident radiation during the growing season and annual equilibrium evapotranspiration (a function of net radiation and temperature). Aridity was (inversely) described by the moisture index ( $M I$; the ratio between precipitation and potential evapotranspiration, $P E T$ ), with PET calculated in two ways: $P E T_{\mathrm{F}}$ (using the PenmanMonteith formulation; FAO, 2004) and $P E T_{\mathrm{Q}}$ (using equilibrium evapotranspiration to represent potential evapotranspiration;
Wang et al., 2014), yielding $M I_{\mathrm{F}}$ and $M I_{\mathrm{Q}}$, respectively (see Table S3-1 in Appendix S3 for a full list of descriptions).

\section{Edaphic drivers}

Soil variables that express long-term pedogenetic characteristics, to which plants adapt over generations, can be contrasted with those reflecting more rapid within-season changes (Peltzer et al., 2010). We considered only the former type, choosing to avoid fast-changing variables like $\mathrm{N}$ mineralization rate. Key edaphic determinants of plant processes include the texture and structure of soils, ion exchange capacity and macronutrient content of the top soil layer (see Table S3-1 in Appendix S3 for a full list). Soil data were extracted using the 'raster' package in R 3.0.1 (R Core Team, 2013) from three spatially interpolated global datasets. SoilGrids (0-22.5 cm layer, ISRIC, 2013) - an automated system that produces soil datasets derived from digital soil mapping (Hengl et al., 2014) - and the Harmonized World Soil Database (0-30 cm layer, FAO et al., 2012) are interpolated at $30^{\prime \prime} \times 30^{\prime \prime}$ resolution and provide the majority of soil variables (organic matter content, $\mathrm{pH}$, cation exchange capacity, texture and structure of soils). Soil $\mathrm{N}$ content and $\mathrm{C}: \mathrm{N}$ ratio, aluminium saturation and the available water holding capacity of the $0-20 \mathrm{~cm}$ layer were extracted from the $5^{\prime} \times 5^{\prime}$ ISRIC-WISE dataset (Batjes, 2012). If several soil types occurred within a grid cell, soil property estimates correspond to the area-weighted profile mean.

We also constructed a dataset for soil available $\mathrm{P}$ concentration $\left(P_{\text {avail }}\right)$ based on information from several sources (see Appendix S4 for details). In brief, we first assembled geolocated soil profiles from several soil phosphorus datasets (e.g. Batjes, 2011a; Shangguan et al., 2013; Tóth et al., 2013). When the distance from the nearest profile was less than $100 \mathrm{~km}$ we recorded the nearest soil profiles for each site in the plant trait dataset. Otherwise, we did a literature survey to search for data from closer locations. The values for $P_{\text {avail }}$ were harmonized to a single chemical extraction method (Bray \& Kurtz, 1945) based on published conversion factors. The broad-scale reliability of the harmonized $P_{\text {avail }}$ data was confirmed using categorical information: the global distribution of soil P retention potential (Batjes, 2011b) and the weathering stage associated with the soil orders of plant trait sites (Appendix S4).

Climate conditions varied widely among the 288 study sites: mean annual temperature ranged from -21.4 to $27.3^{\circ} \mathrm{C}$, annual precipitation from 23 to $5406 \mathrm{~mm}$ and mean annual $\mathrm{MI}$ from 0.09 to 6.54 , covering most of the temperature-rainfall space in which higher plants are found. Soil conditions also varied widely: total exchangeable bases (TBA) ranged from 75 to $1801 \mathrm{cmol} \mathrm{kg}^{-1}$, soil $\mathrm{pH}$ from 3.5 to 8.4 , total soil $\mathrm{N}\left(N_{\text {tot }}\right)$ from 0.3 to $16.7 \mathrm{~g} \mathrm{~kg}^{-1}, P_{\text {avail }}$ from 0.2 to $960 \mathrm{mg} \mathrm{P}_{2} \mathrm{O}_{5} \mathrm{~kg}^{-1}$ and clay fraction from 2 to $42 \%$ (Fig. S3-2 in Appendix S3).

\section{Data analysis}

\section{Data selection and transformation}

Being right-skewed, all plant traits were log-transformed. Environmental variables were subjected to the Yeo-Johnson trans- 
formation ('car' package; $\mathrm{R}$ core team, 2013); this provides a powerful way of reducing skewness and can be applied to variables that include negative values (see details in Table S6-1 in Appendix S6).

Five methodological steps were defined, each one dedicated to one of the five questions presented in the introduction. The details, benefits and limitations of each step are described in Table S6-2 in Appendix S6.

Step 1. Defining key dimensions of soil fertility and quantifying their relationships with leaf traits

A general theoretical approach based on existing conceptual models of soil and ecosystem development over geological timescales (Vitousek, 2004; Peltzer et al., 2010; Huston, 2012) was used to predict relationships between soil $\mathrm{pH}$ and each of several main facets of soil fertility, i.e. TBA, organic C content $\left(C_{\text {org }}\right)$, $N_{\text {tot }}, P_{\text {avail }}$ and available water holding capacity $(A W H C)$. We compared the observed relationships with the predicted ones, first fitting quadratic regressions (to accommodate nonlinearity) and then linear models whenever the square term of the quadratic model was non-significant (see Appendix S8 for more details). A systematic analysis of the impact of each soil and climate variable on each trait was realized (Figs 2 \& S8 in Appendix S8). In mixed models, the fixed-effect term was the soil or climate variable allocated to each site; site and species were considered as random intercepts (making standard assumptions of normality, independence and homoscedasticity). The site and species effects were included to reflect the hierarchical structure (multiple species at multiple sites) and the unbalanced and nested structure (different number of samples/species between sites) in the sampling design. Models were fitted using the $\mathrm{R}$ package 'lme4' and adjusted $r^{2}$ values $\left(r_{\mathrm{a}}^{2}\right)$ were calculated following Moles et al. (2009).

Step 2. Selecting the most important climatic and soil variables for explaining leaf trait variation

Next, for each trait we used a stepwise multiple mixed regression model to select up to four explanatory variables from among the various available climate and soil variables (Table S3-1 in Appendix S3), by minimizing the Akaike information criterion (Legendre \& Legendre, 2012). Site and species effects were treated as random factors. The R packages 'Ime4' and 'MuMIn' were used.

Step 3. Quantifying unique and joint effects of soils and climate for explaining variation in each leaf trait

In this step we used variation partitioning and Venn diagrams (Legendre \& Legendre, 2012) to partition the total variation explained in each leaf trait into components explained uniquely by the matrix of soil variables, uniquely by the matrix of climate variables or (jointly) explained by the combined soil and climate matrices. For these analyses we used the soil and climate variables identified as part of Step 2 (see Table 1 for the selected soil and climate variables) and multiple mixed regression models. The unique effect of soil (or climate) was calculated as the $r_{\mathrm{a}}^{2}$ difference between the full model and the climate (or soil) model. The joint effect of soil and climate was calculated as the difference between the summed $r_{\mathrm{a}}^{2}$ of soil and climate models and the $r_{\mathrm{a}}^{2}$ of the full model.

Step 4. Quantifying the explanatory power of soils and climate for the matrix of leaf traits

Photosynthetic rates can be understood as the outcome of coordinated investments in water transport capacity, needed to support a high rate of $g_{s}$, versus Rubisco carboxylation capacity, indexed by Rubisco activity $\left(V_{\text {cmax }}\right)$ - potentially related to both $N_{\text {area }}$ (e.g. Wright et al., 2003) and $P_{\text {area }}$ (e.g. Niinemets et al., 1999). To test whether and how soil and climate variables can distinctively promote these different drivers of leaf photosynthesis it is important to consider the relationships among leaf traits in the same analysis (Steps 4 and 5). First, we used redundancy analysis (the 'vegan' package; R Core Team, 2013) to quantify how much of the variation in the matrix of leaf traits could be explained by the matrices of the most important soil and climate variables selected at Steps 2 and 3. For leaf traits we used $A_{\text {area }}, g_{\mathrm{s}}, N_{\text {area }}$ and $S L A$ (giving a dataset of 647 species from 99 sites). $P_{\text {area }}$, with its considerably smaller sample size, was left out of this analysis.

Step 5. Disentangling direct and indirect effects of leaf traits, soil and climate on photosynthetic capacity

We used path analysis (the 'lavaan' package; R Core Team, 2013) to explore how variation among species in $A_{\text {area }}$ can best be understood as driven by both direct and indirect effects of $g_{s}$, $N_{\text {area }}$ SLA and the key environmental drivers identified in previous steps, selecting the model that was the least different from the observations ( $P$-value $>0)$. Note that Steps 4 and 5 are complementary (Table S6-1 in Appendix 6), with Step 4 testing the relationships between matrices without a priori constraints, while Step 5 allowed us to evaluate possible causal effects of soil independent of climate on leaf traits (Legendre \& Legendre, 2012).

\section{RESULTS}

\section{Step 1a. Two dimensions of soil 'fertility'}

Figure 1(a)-(e) summarizes expected relationships between soil $\mathrm{pH}$ and each of several dimensions of soil fertility. From high to low soil $\mathrm{pH}$ (right to left), i.e. conceivably from young soils where the parent rock supplies cations and phosphorus to older and more highly weathered soils, remote from the parent material but enriched in SOM, Fig. 1 indicates the following. 1. A decrease of total exchangeable bases, but an increase in $\mathrm{Al}$ and Fe content (Fig. 1a).

2. An increase in total $\mathrm{C}$ and $\mathrm{N}$ and $A W H C$, due to the accumulation of SOM (Fig. 1b-d). In addition, soil available nitro- 
Table 1 Multiple mixed regression relationships between area-based leaf functional traits ( $A_{\text {area }}$, leaf photosynthetic rate; $g_{s}$, stomatal conductance; $N_{\text {area, }}$ leaf nitrogen content; $P_{\text {area }}$, leaf phosphorus content; and SLA, specific leaf area) and soil and climate subsets of environmental variables.

\begin{tabular}{|c|c|c|c|c|c|c|c|c|}
\hline Trait & Factors & $n$ & $r^{2}$ & AIC & $F$, factor 1 & $F$, factor 2 & $F$, factor 3 & $F$, factor 4 \\
\hline \multicolumn{9}{|c|}{ Climate model } \\
\hline$A_{\text {area }}$ & $M I_{\mathrm{Q}}+T M P_{\text {range }}+S U N_{\max }$ & 2337 & $0.098^{* * *}$ & -886 & $\downarrow 20.8^{\star * *}$ & $\downarrow 5.6^{*}$ & $\uparrow 3.5\left(^{*}\right)$ & - \\
\hline$g_{s}$ & $T M P_{\max }+T M P 0_{\mathrm{nb}}+P P T_{\text {season }}$ & 1035 & $0.102^{\star * *}$ & -38 & $\uparrow 8.7^{\star *}$ & $\downarrow 5.4^{*}$ & $\uparrow 7.9^{* *}$ & - \\
\hline$N_{\text {area }}$ & $M I_{Q}+T M P_{\text {range }}$ & 1643 & $0.178^{\star * *}$ & -1726 & $\downarrow 53.9^{* * *}$ & $\downarrow 5.5^{*}$ & - & - \\
\hline$P_{\text {area }}$ & $M I_{\mathrm{Q}}+R H$ & 512 & $0.312^{* * *}$ & -353 & $\downarrow 27.9^{* * *}$ & $\uparrow 16.3^{\star * *}$ & - & - \\
\hline$S L A$ & $S U N_{\max }+T M P_{\text {max }}+T M P O_{\mathrm{nb}}$ & 1965 & $0.146^{\star \star *}$ & -1474 & $\downarrow 41.1^{\star * *}$ & $\uparrow 13.6^{* * *}$ & $\downarrow 30.8^{\star * *}$ & - \\
\hline \multicolumn{9}{|c|}{ Soil model } \\
\hline$A_{\text {area }}$ & $p H+N_{\text {tot }}+C E C S$ & 2337 & $0.195^{\star * \star}$ & -928 & $\uparrow 90.0^{* * *}$ & $\uparrow 19.1^{* * *}$ & $\downarrow 25.6^{* * *}$ & - \\
\hline$g_{s}$ & $p H+N_{\text {tot }}+C E C S+P_{\text {avail }}$ & 1035 & $0.241^{\star * \star}$ & -128 & $\uparrow 28.0^{* * *}$ & $\uparrow 24.8^{* * *}$ & $\downarrow 19.3^{* * *}$ & $\downarrow 67.0^{* * *}$ \\
\hline$N_{\text {area }}$ & $p H+N_{\text {tot }}+S A L T$ & 1643 & $0.193^{* * *}$ & -1736 & $\uparrow 38.0^{* * *}$ & $\downarrow 5.5^{\star}$ & $\uparrow 9.2^{* *}$ & - \\
\hline$P_{\text {area }}$ & $p H+P_{\text {avail }}+S A L T+S A N D$ & 512 & $0.440^{* \star *}$ & -361 & $\uparrow 8.8^{\star *}$ & $\uparrow 19.5^{* * *}$ & $\uparrow 6.7^{\star}$ & $\downarrow 7.2^{* *}$ \\
\hline SLA & $p H+N_{\mathrm{tot}}+S I L T+B U L K$ & 1965 & $0.159^{* * *}$ & -1461 & $\downarrow 15.4^{* * *}$ & $\uparrow 3.2\left(^{*}\right)$ & $\uparrow 14.4^{* * *}$ & $\downarrow_{5.0^{*}}$ \\
\hline
\end{tabular}

$\left.{ }^{*}\right) P<0.1 ;{ }^{\star} P<0.05 ;{ }^{* *} P<0.01 ;{ }^{* * *} P<0.001$.

Following a stepwise procedure criterion selecting the most important variables among 26 climate or 20 soil variables (see Materials and Methods and Table S3-1 in Appendix S3 for details) based on an Aikaike information criterion (AIC), linear mixed regression models were used to measure the impact of environmental variables on each trait. Site and species were treated as random factors (intercepts). The adjusted $r^{2}$ and AIC are provided for each regression model (see Materials and Methods for details of $r^{2}$ calculation). $F$ - and $P$-values for Type III error models are specified for each fixed soil factor. Factors 1 to 4 correspond to the rank of each fixed factor that was selected in the regression model. Leaf trait variables were log-transformed and environmental variables were power-transformed as described in Materials and Methods. Arrows indicate the sign of the coefficient estimate. See Tables S8-4 \& 8-5 in Appendix S8 for equation details.

$M I_{\mathrm{Q}}$, moisture index representing the ratio between annual precipitation and equilibrium evapotranspiration; $T M P_{\text {range, }}$ mean diurnal temperature range; $S U N_{\max }$, maximum monthly fractional sunshine duration; $T M P_{\max }$, maximal monthly temperature; $T M P 0_{\mathrm{nb}}$, number of days with daily temperature above $0{ }^{\circ} \mathrm{C} ; P P T_{\text {season }}$, seasonality of precipitation; $R H$, relative humidity; $\mathrm{pH}$, soil $\mathrm{pH} ; N_{\text {tot }}$, soil total nitrogen content; $C E C S$, cation exchange capacity, $P_{\text {avail, }}$ available soil phosphate content; SALT, soil salinity; SAND, soil sand content; SILT, soil silt content; BULK, soil bulk density.

gen $\left(N_{\text {avail }}\right)$ is expected to follow $N_{\text {tot }}$ up to a maximal value at intermediate $\mathrm{pH}$, where optimal conditions for microbial nitrogenase activity are reached. Thereafter, $N_{\text {avail }}$ decreases steeply with increasing $\mathrm{pH}$ (Walker \& Syers, 1976).

3. A decrease in $P_{\text {tot }}$ (Lambers et al., 2008; Fig. 1e) with increasing distance (and time) to the parent rock, where $\mathrm{P}$ is sourced. However, $P_{\text {avail }}$ may show a humped distribution as $\mathrm{P}$ can co-precipitate with $\mathrm{Ca}$ at high $\mathrm{pH}$ and with $\mathrm{Fe}$ and $\mathrm{Al}$ at low $\mathrm{pH}$.

Our data substantially matched these predictions (Fig. 1f-i). As soil $\mathrm{pH}$ increased, so did TBA, soil base saturation and, to a lesser extent, soil carbonate content, while $\mathrm{Al}$ saturation decreased (correlations given in Table S7-3 in Appendix S7). Quadratic relationships accounted for the relationships between $\mathrm{pH}$ and $C_{\text {org }}$ and between $\mathrm{pH}$ and $N_{\text {tot }}$ (Fig. 1g,h). AWHC and the climatic MI decreased linearly with $\mathrm{pH}$ (Fig. 1i). Contrary to expectation, however, no relationship was found between $\mathrm{pH}$ and $P_{\text {avail }}$ (Fig. 1j). High $P_{\text {avail }}$ was encountered at high-pH sites that were characterized by a low carbonate content, but also at low $\mathrm{pH}$ sites characterized by low $\mathrm{Al}$ saturation.

These relationships suggested the existence of two principal dimensions of soil fertility. Soil $\mathrm{pH}$ indexes a first dimension along which exchangeable bases, $N_{\text {avail }}, C_{\text {org }}, N_{\text {org }}$ and AWHC covary, and the availability of micronutrients and $\mathrm{N}$ trade off with the availability of water. A second, largely independent, dimension is indexed by $P_{\text {avail }}$, which covaries negatively with Al saturation, soil depth and clay content, and positively with gravel content (Table S7-3 in Appendix S7).

\section{Step 1b. Relationships between individual leaf traits and soil variables}

We quantified bivariate relationships between the five photosynthetic traits and five soil variables $\left(P_{\text {avail }}\right.$ and four variables from fertility dimension 1: soil $\mathrm{pH}, C_{\text {org }}, N_{\text {tot }}$ and AWHC). $A_{\text {area }}, N_{\text {area }}$ and $P_{\text {area }}$ all increased linearly with soil $\mathrm{pH}\left(r^{2}=0.12-0.17\right.$; Fig. 2), while SLA decreased $\left(r^{2}=0.06\right)$. Note that the corresponding mass-basis traits also increased with soil $\mathrm{pH}$, but with notably lower $r^{2}$ than on an area basis (all $r^{2}<0.03, P<0.002$; not shown).

As expected from their negative covariation with soil $\mathrm{pH}$ along fertility dimension 1 (Fig. 1), $C_{\text {org }}, N_{\text {tot }}$ and $A W H C$ affected $S L A, N_{\text {area }}, P_{\text {area }}$ and $A_{\text {area }}$ in the directions opposite to the pH-related effects (Fig. 2). The pH-leaf trait relationships all remained significant after accounting for covariation with mean annual temperature and precipitation (dashed lines in Fig. 2). However, this was not the case for relationships involving $C_{\text {org }}$, $N_{\text {tot }}$ and $A W H C$.

Stomatal conductance, $g_{s}$, showed little patterning along fertility dimension 1 , the strongest relationship being a very weak dependence on soil $\mathrm{N}$ ( $r^{2}=0.02$; Fig. 2l). By contrast, both $g_{\text {s }}$ (negative) and $P_{\text {area }}$ (positive) showed strong patterning along fertility dimension 2 (i.e. varying with $P_{\text {avail }}$ ). These relationships were little changed by concurrently accounting for climate (dashed fitted lines, Fig. 2v,x). Unexpectedly, $P_{\text {avail }}$ was the strongest single environmental predictor of $g_{s}$ (the strongest 
Figure 1 Theoretical $(\mathrm{a}-\mathrm{d})$ and observed $(\mathrm{e}-\mathrm{h})$ relationships between soil variables describing the availability of the main resources (cations, nitrogen, phosphorus and water) that plants use in photosynthesis. Soil $\mathrm{pH}_{\text {water }}$ is considered here as a proxy of the stage of soil evolution, and thus as a key variable expressing the dynamics of soil resources between the different sites used in this study. The various panels show dynamics of: $(a, f)$ total soil exchangeable bases; (b, g) soil organic $\mathrm{C}$ content; $(\mathrm{c}, \mathrm{h})$ soil available nitrogen and total $\mathrm{N}$ content; $(\mathrm{d}, \mathrm{i})$ soil available water holding capacity, considering also precipitation $(P P T)$ and moisture index $(M I)$; and $(e, j)$ soil available phosphorus and total $\mathrm{P}$ content (prediction for $\mathrm{P}_{\text {tot }}$ based on Lambers et al., 2008). Regression models ( $n=288$ sites): (f) $\log (T B A)=-0.40+0.22 \cdot \mathrm{pH}, r^{2}=0.50$; (g) $\log \left(C_{\text {org }}\right)=1.09-0.04 \cdot \mathrm{pH}^{2}$ $+0.31 \cdot \mathrm{pH}, r^{2}=0.33$; (h) $\log \left(N_{\mathrm{tot}}\right)=-0.91$ $-0.05 \cdot \mathrm{pH}^{2}+0.47 \cdot \mathrm{pH}, r^{2}=0.12$; (i) $\log (A W H C)=1.40-0.38 \cdot \mathrm{pH}, r^{2}=0.10$; $\mathrm{pH}=5.9-2.1 \cdot \log \left(M I_{\mathrm{Q}}\right), r^{2}=0.54$. All relationships were significant at the $P$ $=0.001$ level. $O M$, organic matter; TBA, total exchangeable bases; $A W H C$, available water holding capacity.
Theoretical relationships
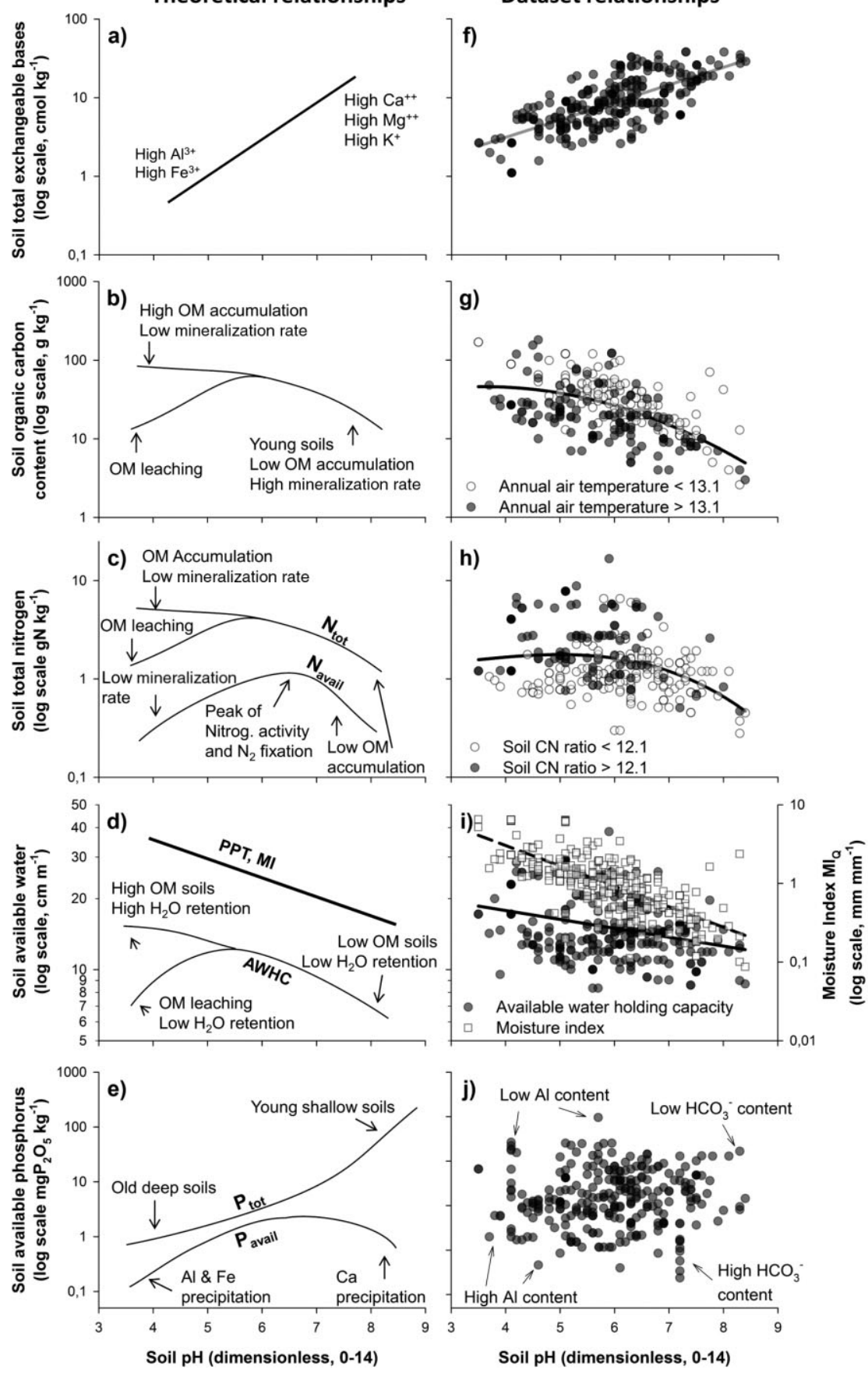

climate predictor being precipitation seasonality, $r^{2}=0.06$; Fig. S8-1 in Appendix S8). Indeed, the single strongest predictor for each leaf trait was a soil variable ( $\mathrm{pH}$ for $A_{\text {area }}, N_{\text {area }}$ and $S L A$; $P_{\text {avail }}$ for $g_{\mathrm{s}}$ and $P_{\text {area; }}$ full details in Fig. S8-1 in Appendix S8).

\section{Step 2. Selection of the most important soil and climate variables}

As in bivariate relationships (Figs S8-1 \& S8-2 in Appendix S8) but using stepwise multiple regressions, soils did a better job than climate for explaining variation in each trait, and in the case of $A_{\text {area }}$ and $g_{s}$ soils explained more than twice as much variation as climate $\left(r^{2}=0.195\right.$ and 0.241 vs. 0.098 and 0.102 , respectively; Table 1 ). As judged by $F$-values, soil $\mathrm{pH}$ and $P_{\text {avail }}$ were the two soil variables that had the greatest effect on leaf traits, while $M I_{\mathrm{Q}}$ was the most important climate variable (Table 1).

\section{Step 3. Quantification of unique and joint effects of soil and climate on leaf traits}

Using variation partitioning, $21-31 \%$ of variation was explained for each trait except $P_{\text {area }}$ (54\%) (Fig. 3). Overall, soils explained more variation in leaf traits than did climate, with this effect 

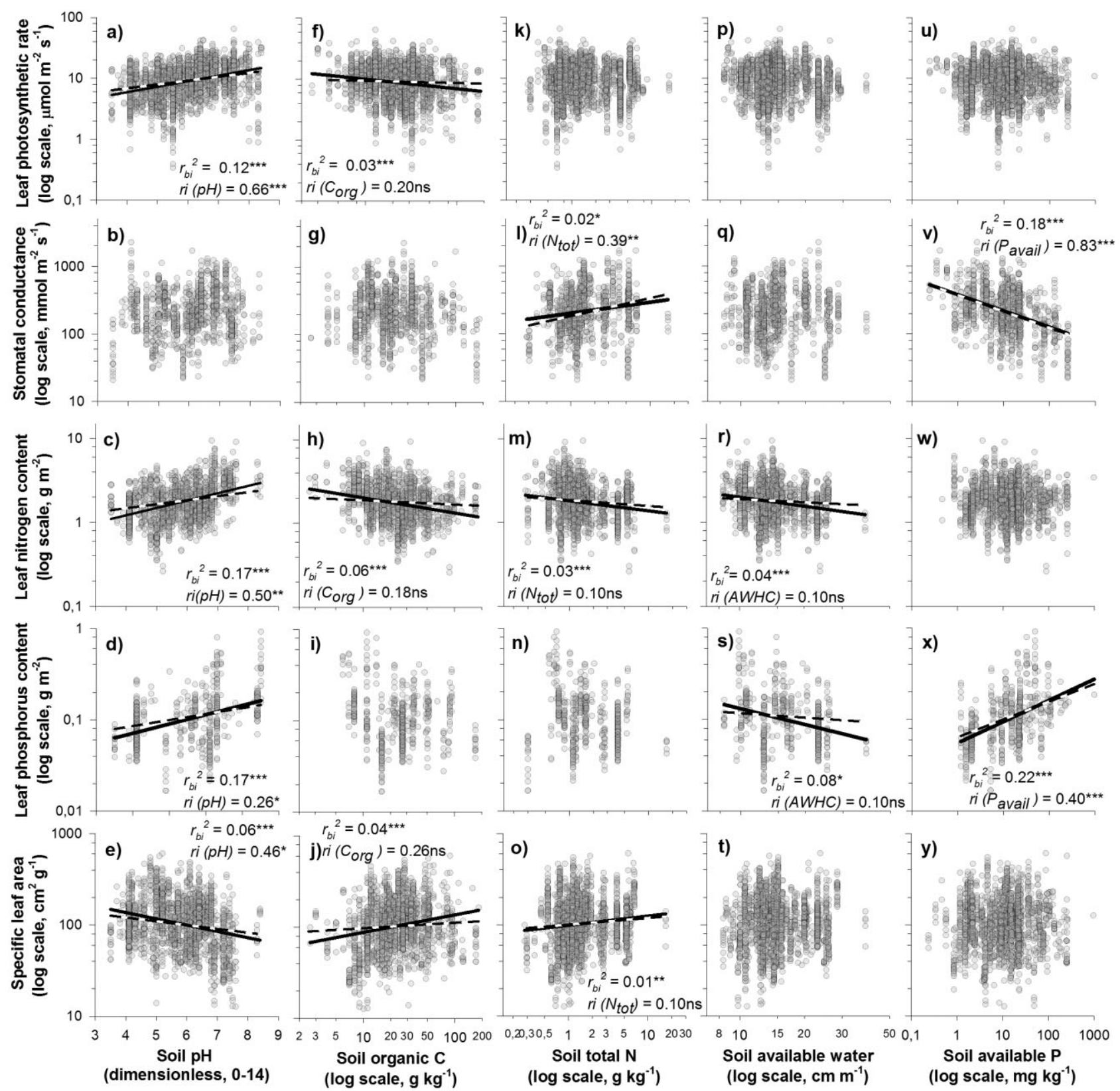

Figure 2 Relationships between area-based leaf photosynthetic traits and soil variables considered in the theoretical soil development model (Fig. 1). Leaf photosynthetic rate ( $n=2400 ; \mathrm{a}, \mathrm{f}, \mathrm{k}, \mathrm{p}, \mathrm{u})$, stomatal conductance $(n=1070 ; \mathrm{b}, \mathrm{g}, \mathrm{l}, \mathrm{q}, \mathrm{v})$, leaf nitrogen content $(n=1704 ; \mathrm{c}, \mathrm{h}, \mathrm{m}, \mathrm{r}, \mathrm{w})$, leaf phosphorus content $(n=532 ; \mathrm{d}, \mathrm{i}, \mathrm{n}, \mathrm{s}, \mathrm{x})$ and specific leaf area $(n=1964 ; \mathrm{e}, \mathrm{j}, \mathrm{o}, \mathrm{t}, \mathrm{y})$ regressed on soil pH $(a-e)$, soil organic $C$ content $(f-j)$, soil total nitrogen content $(k-o)$, soil available water holding capacity $(p-t)$ and soil available phosphate content $(\mathrm{u}-\mathrm{y})$ according to linear relationships using mixed regression models with site and species as random factors. Solid lines correspond to the significant regressions for which statistical information from mixed regression models $\left(r_{\mathrm{bi}}{ }^{2}\right.$ and $P$-value $)$ are reported on each caption. Equations are reported below. Dashed lines correspond to the impact of the soil variable in multiple mixed regression models, including two important climatic variables that can affect leaf traits (mean precipitation, $P P T_{\text {mean }}$, and $T M P_{\text {mean, }}$, Wright $e$ t al., 2004). These conditional slopes ('visreg' package; R Core Team, 2013) indicated the bivariate soil-trait relationship calculated while holding constant (at their median) the two climate variables. Significance of the soil variable and its relative importance, ri ('relaimpo' package, R Core Team, 2013), in the multiple mixed regression model is reported on each caption. Statistical significance is indicated using asterisks: ${ }^{\star} P<0.05 ;{ }^{* \star} P<0.01 ;{ }^{* *} P<0.001$. Equations of bivariate relationships: $(\mathrm{a}) \log \left(A_{\text {area }}\right)=0.49+\left(8.09 \times 10^{-2}\right) \cdot \mathrm{pH}$; (c) $\log \left(N_{\text {area }}\right)=-0.18+\left(7.47 \times 10^{-2}\right) \cdot \mathrm{pH}_{;}(\mathrm{d}) \log \left(P_{\text {area }}\right)=-1.45+\left(9.02 \times 10^{-2}\right) \cdot \mathrm{pH} ;(\mathrm{e}) \log (S L A)=2.26-\left(4.26 \times 10^{-2}\right) \cdot \mathrm{pH} ;(\mathrm{f})$ $\log \left(A_{\text {area }}\right)=1.15-0.13 \cdot \log \left(C_{\text {org }}\right) ;(\mathrm{h}) \log \left(N_{\text {area }}\right)=0.48-0.16 \cdot \log \left(C_{\text {org }}\right) ;(\mathrm{j}) \log (S L A)=1.84+0.12 \cdot \log \left(C_{\text {org }}\right) ;(1) \log \left(g_{\mathrm{s}}\right)=2.29+0.18 \cdot \log \left(N_{\text {tot }}\right)$; (m) $\log \left(N_{\text {area }}\right)=0.28-0.15 \cdot \log \left(N_{\text {tot }}\right) ;(\mathrm{o}) \log (S L A)=1.99+0.11 \cdot \log \left(N_{\text {tot }}\right) ;(\mathrm{q}) \log \left(g_{\mathrm{s}}\right)=2.57-0.24 \cdot \log \left(P_{\text {avail }}\right)$; (s) $\log \left(P_{\mathrm{a}}\right)=-1.16+0.19 \cdot \log \left(\mathrm{P}_{\text {avail }}\right) ;(\mathrm{w}) \log \left(N_{\text {area }}\right)=0.66-0.34 \cdot \log (A W H C) ;(\mathrm{x}) \log \left(P_{\mathrm{a}}\right)=-0.37-0.47 \cdot \log (A W H C) \cdot A W H C$, available water holding capacity; $S L A$, specific leaf area. 


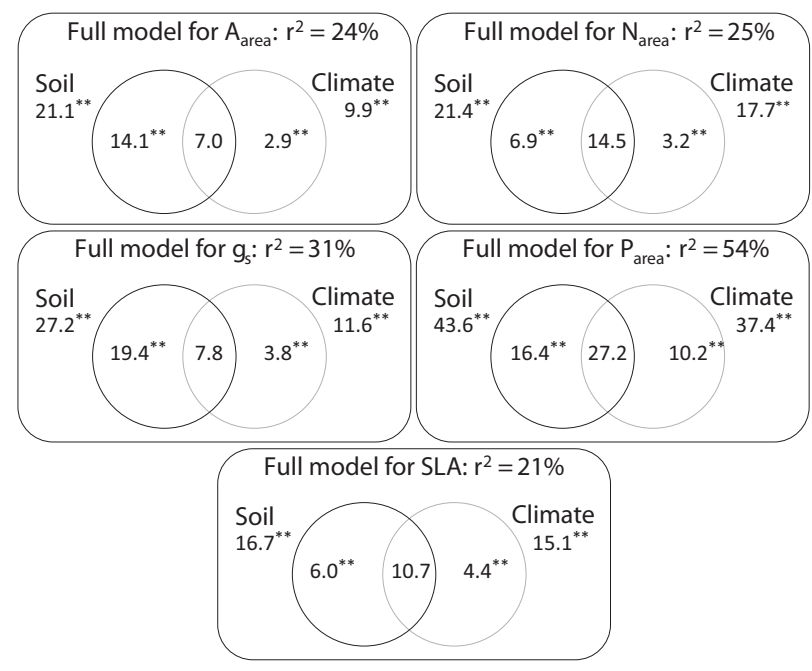

Figure 3 Partitioning of the respective variation in leaf photosynthetic rate $\left(A_{\text {area }}\right)$, stomatal conductance $\left(g_{\mathrm{s}}\right)$, leaf nitrogen content $\left(N_{\text {area }}\right)$, leaf phosphorus content $\left(P_{\text {area }}\right)$ and specific leaf area (SLA) between the unique effect of soil, the unique effect of climate and the joint effect of soil and climate variables. Multiple mixed regressions were used to compute the adjusted $r^{2}$ of the fixed effects (climate and soil variables). Site and species were considered as random factors. The soil and climate variables used in these analyses were the ones revealed to be most relevant by a stepwise model selection procedure: $M I_{\mathrm{Q}}, S U N_{\max }$, $T M P_{\text {max }}, T M P 5_{\text {nb }}, P P T_{\text {season }}, R H, T M P_{\text {range, }} \mathrm{pH}, N_{\text {tot }}, P_{\text {avail }}, S I L T$, $S A N D, B U L K, C E C S$ and SALT, are respectively moisture index, maximum monthly fractional sunshine duration, maximal monthly temperature, number of days with daily temperature above $5{ }^{\circ} \mathrm{C}$, seasonality of precipitation, relative humidity, mean diurnal temperature range, soil $\mathrm{pH}$, soil total nitrogen content, available soil phosphate content, soil silt and sand contents, soil bulk density, cation exchange capacity and soil salinity. Statistical significance is indicated using asterisks: ${ }^{\star \star} P<0.01$.

being strongest for $A_{\text {area }}$ and $g_{s}$. For the other traits $\left(N_{\text {area }}, P_{\text {area }}\right.$ and $S L A$ ), about half the total variation explained was accounted for by the common patterns of variation in climate and soils (the 'joint' effects).

\section{Step 4. Multidimensional covariation between soils, climate and leaf traits}

We used redundancy analysis to better understand how the structure in the matrix of leaf traits could be explained using the structure in the matrix of the most important soil and climate variables (selected at Step 2). Note, first, that $A_{\text {area }}$ covaried significantly with $g_{s}, N_{\text {area }}, P_{\text {area }}$ and SLA $\left(r^{2}=0.76,0.14,0.07,0.01\right.$, respectively). Thirty per cent of the variation in the four-trait matrix was explained by soils and climate (Fig. 4). Vectors representing variation in $N_{\text {area }}$ and $g_{s}$ were orthogonal and clearly associated with a number of environmental variables, while the vectors for $A_{\text {area }}$ and SLA were also orthogonal to each other, and less clearly associated with environmental variables. In this analysis $N_{\text {area }}$ was mainly explained by soil $\mathrm{pH}$ and by $M I_{\mathrm{Q}}$, with high values of $N_{\text {area }}$ found in arid sites on soils with high pH. $g_{s}$ was mainly explained by $P_{\text {avail }}$, bulk density, sand content and growing season temperature, with high values of $g_{\mathrm{s}}$ found in warm sites on compact soils with low values of $P_{\text {avail }}$.

\section{Step 5. Interdependences between key site variables and photosynthetic traits}

Three environmental variables were repeatedly shown to be key for explaining variation in leaf traits: soil $\mathrm{pH}$, soil available $\mathrm{P}$, and $M I$. We used path analyses to explore the interdependences between these variables and the key photosynthetic traits $A_{\text {area }}$ $N_{\text {area }}$ and $g_{s}$. The most parsimonious path analysis model explained $64 \%$ of the variation in $A_{\text {area }}$ (Fig. 5). Figure 5 shows that high $M I$ promotes acid soils. High $M I$ and acid soils both (independently) promote low $N_{\text {area }}$. High $P_{\text {avail }}$ and arid climate both (independently) promote low $g_{s}$. Both $g_{s}$ and $N_{\text {area }}$ (independently) determine $A_{\text {area }}$ in accord with theory (Wright et al., 2003). There are also significant direct effects of $M I$ and $\mathrm{pH}$ on $A_{\text {area }}$ that are in the same direction as, but not accounted for by, the effects of $N_{\text {area }}$ and $g_{s}$. Note that when SLA was added (considering its impact on $N_{\text {area }}, g_{\mathrm{s}}$ and $A_{\text {area }}$, and depending on $M I_{\mathrm{Q}}$ and $\mathrm{pH}$ ), the models were consistently far weaker; hence they are not presented.

\section{DISCUSSION}

Climate plays a key role in soil development (Jenny, 1941); this leads to correlations among present-day soil and climate variables, and interactive effects of soils and climate on plant traits. We identified two main dimensions of environmental variation, key to understanding variation in leaf photosynthetic traits, which we discuss in relation to concepts of soil and ecosystem development.

\section{A soil pH-aridity dimension}

The first dimension was most strongly associated with soil $\mathrm{pH}$ (and exchangeable cations) decreasing with increasing precipitation and $M I_{\mathrm{Q}}$. Higher values of $N_{\text {area }}, P_{\text {area }}$ and $A_{\text {area }}$ were found in more arid sites and on soils with a higher $\mathrm{pH}$, but $g_{\mathrm{s}}$ was unrelated to this dimension.

The tendency for species to have higher $N_{\text {area }}$ (and, less so, $\left.P_{\text {area }}\right)$ at drier sites is well known (Field et al., 1983; Schulze et al., 1998), and accords with theory which predicts the predominance of high- $N_{\text {area }}$ strategies as a means to economise on water use during photosynthesis (Farquhar et al., 2002; Wright et al., 2003, discussed further below). By contrast, broad-scale patterning of leaf traits with soil $\mathrm{pH}$ has rarely been reported (but see Han et al., 2011) and is correspondingly less well understood. These $\mathrm{pH}$-related relationships were not simply secondary correlations flowing from the well-documented regional negative relationships between soil $\mathrm{pH}$ and precipitation, but probably relate to non-climatic determinants of soil $\mathrm{pH}$, like parent rock and topography (Jenny, 1941). Soil pH is implicated in many soil chemical, enzymatic and microbial processes that affect the 


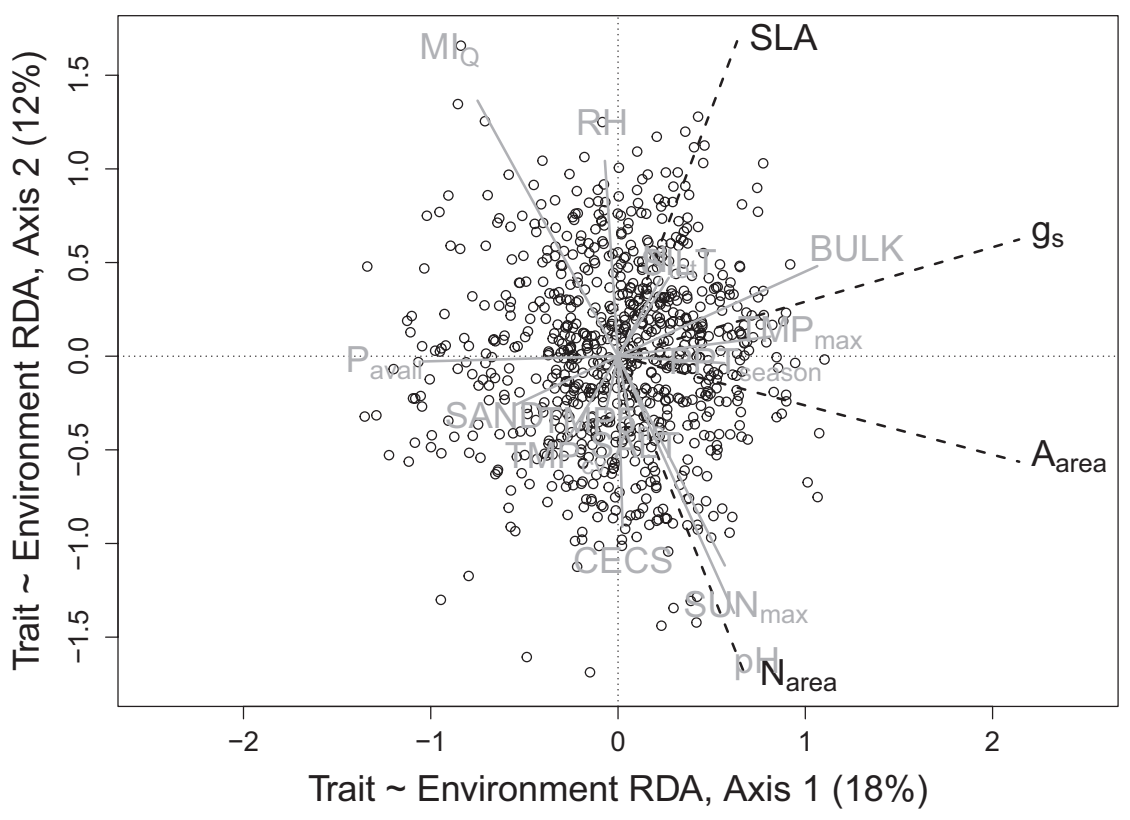

Figure 4 Redundancy analysis predicting the composition and structure of leaf photosynthetic traits $\left(A_{\text {area }}, N_{\text {area }}, g_{s}\right.$ and $S L A$ ) from the composition and structure of the most important soil and climate variables (selected by a stepwise procedure, see caption to Fig. 3). Abbreviations are defined in the caption to Fig. 3.

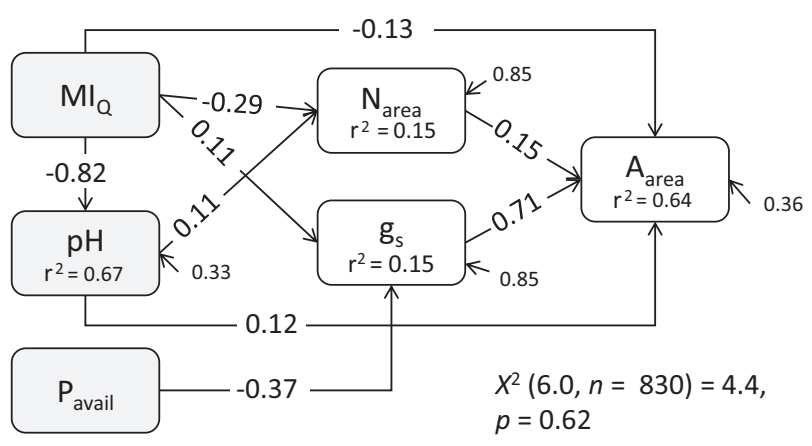

Figure 5 Path analysis depicting the direct and indirect effects of the main environmental predictors of leaf photosynthetic rate $A_{\text {area }}$ through its covariation with stomatal conductance $\left(g_{\mathrm{s}}\right)$ and leaf nitrogen content $\left(N_{\text {area }}\right)$. Environmental variables were selected based on the results of Fig. 4 and were soil $\mathrm{pH}(\mathrm{pH})$, moisture index $\left(M I_{\mathrm{Q}}\right)$ and soil available phosphorus content $\left(P_{\text {avail }}\right)$. The path coefficients are the simple standardized regression coefficient. The goodness-of-fit and the unexplained variance of $A_{\text {area }}, N_{\text {area }}$ and $g_{s}$ are given. A Pearson correlation between $N_{\text {area }}$ and $g_{\mathrm{s}}$ was tested and was not significant.

availability of micronutrients and nutrients (for a review see Sinsabaugh \& Follstad Shah, 2012), and therefore so are $N_{\text {area }}$ and $P_{\text {area. }}$. Considered across a broad gradient of soil types, higher $\mathrm{pH}$ should generally equate to faster and/or higher availability of nutrients held in SOM and reduce the overall acquisition costs of $\mathrm{N}$ and thus the costs of achieving a given biochemical capacity for photosynthesis.

Conversely, higher SOM concentration (indexed by $C_{\text {org }}$ or $N_{\text {tot }}$ ) does not necessarily denote higher $\mathrm{N}$ availability. In acid conditions SOM becomes recalcitrant, and $\mathrm{N}$ availability is correspondingly low (Jenny, 1941). Hence, here and elsewhere (Santiago et al., 2005; Ordoñez et al., 2009) we found the counterintuitive result that leaf $\mathrm{N}$ decreased with increasing soil total N.

Interestingly, the first dimension of soil fertility partially associated with the variation of $A_{\text {area }}$ seems to be unrelated to $g_{s}$. Thus, the tendency of plants sampled locally to be strongly co-varying in $A_{\text {area }}$ and $g_{s}$ and hydraulic properties (Reich, 2014) does not hold in the same fashion across very broad climate and soil gradients, supporting the hypothesis that trade-offs between water and nutrient use predominate at larger scales.

\section{The soil available $\mathbf{P}$ dimension}

The second key environmental dimension was represented by $P_{\text {avail }}$ in the topsoil horizon, covarying with the sand content and bulk density of soil and the site temperature (Fig. 4; Tables S7-3 \& 7-4 in Appendix S7). Both leaf $P_{\text {area }}$ and $g_{\mathrm{s}}$ showed strong patterning with this dimension, with higher $P_{\text {area }}$ but lower $g_{s}$ (but not $A_{\text {area }}$ ) on soils with higher $P_{\text {avail }}$.

Our study sites represented a broad range of soil types and $P_{\text {avail }}$, from highly weathered soils where $\mathrm{P}$ limitation is widespread (representing 33\% of our sites, e.g. Oxisols; Table S4-4 in Appendix S4), to less (low) weathered soils with typically higher $P_{\text {avail }}$ (21\% of our sites, e.g. Inceptisols). While the $P_{\text {avail }}$ part of our soil dataset was unavoidably underpinned by fewer soil profile data than for variables such as $\mathrm{pH}$ and $C_{\text {org }}$, our confidence in these data was boosted by observing positive relationships of $P_{\text {avail }}$ with $P_{\text {area }}$ altitude and latitude, and its negative relationships with clay content, soil depth and Al saturation (Table S7-4 in Appendix 7) - echoing relationships known from regional field studies (Walker \& Syers, 1976; Vitousek, 2004).

We have various prospective explanations for the observation that species on soils with higher P tend to team their maximum photosynthetic rates with lower stomatal conductance, but as yet no clear way to identify the most likely explanation, nor to place 
them into an optimality framework as has been done for climate-related effects on $g_{s}$ (e.g. Medlyn et al., 2011).

Experimentally lowering soil nutrient availability is known to stimulate higher root : shoot ratios (see Poorter et al., 2012, for a comprehensive analysis), which may in turn improve plant water balance and hence allow for a higher $g_{s}$. Conversely, at a given root : shoot ratio, an increase in $g_{s}$ in response to nutrient deficiency has been proposed as an evolutionary mechanism to improve plant nutrition, through an increase in the transpiration rate and the mass-flow of water from the surrounding soil (Edwards et al., 1998; Cramer et al., 2009). This 'mass-flow' hypothesis is generally thought to apply more to soil inorganic $\mathrm{N}$ than to the less mobile P (Cramer et al., 2009), but higher $g_{\mathrm{s}}$ has also been observed under $\mathrm{P}$ deficiency for some species (Raven et al., 2004).

Alternatively, in 'least-cost' photosynthetic optimality theory (Wright et al., 2003), water and nitrogen supplies are considered as substitutable resources to secure carbon, and the optimization of $A_{\text {area }}$ involves minimizing the sum of costs for acquiring and using $\mathrm{N}$ and water in photosynthesis. At higher soil $\mathrm{N}$ availability, where the costs of $\mathrm{N}$ acquisition are lower and therefore costs of water acquisition are relatively higher, plants are expected to operate at a given $A_{\text {area }}$ with a higher $N_{\text {area }}$ and lower $g_{s}$. It is conceivable that soil $\mathrm{P}$ and leaf $\mathrm{P}$ also fit into this framework, for example that higher leaf $\mathrm{P}$ enables a higher carboxylation capacity for a given leaf N (Niinemets et al., 1999; Reich et al., 2009). The same prediction (a higher $\mathrm{N}_{\text {area }}$ and/or a lower $g_{\mathrm{s}}$ for a given $A_{\text {area }}$ ) would be made for a scenario where costs of $\mathrm{N}$ acquisition were lower because of higher $\mathrm{N}$ availability due to more alkaline soil. Perhaps all of these effects could come into play in understanding the general trade-off between $V_{\text {cmax }}$ and water use (Farquhar et al., 2002; Wright et al., 2003; Prentice et al., 2014).

\section{Limitations of our analyses}

Underpinning the use of gridded soils data, we made the assumption of a high signal-to-noise ratio and an overall good match between 'actual' and spatial dataset values. Our observations of geography-soil, climate-soil and trait-soil relationships, which were in agreement with many of those observed in the literature with in situ soil variables measured at various scales (see details in Appendix S5 and Table S7-4 in Appendix S7), supported this. Nonetheless, we stress that local-scale variation in soil properties can certainly be large (Yemefack et al., 2005) and that for more detailed assessments, values measured in situ at the respective plant trait sites would be ideal.

While one's ability to reliably tease apart the independent roles of soil and climate is limited in various ways in any statistical analysis (and especially since climate and soils covary) we chose path analysis as the most suitable for identifying causal structures (Legendre \& Legendre, 2012). In combination with and complementary to the other approaches used (see Table S6-2 in Appendix 6 for the benefits and limitations of each statistical method), we provided evidence that soils modify $A_{\text {area }}$, $g_{s}$ and $N_{\text {area }}$ independently of climate. That said, we must not forget the possibility that these patterns may just be (or also be) markers of longer-term and more important factors associated with soil development, like parent rock, topography, soil age and vegetation (Jenny, 1941).

\section{Conclusion}

A key result of our study is that, in a multivariate traitenvironment space (Fig. 4), there are two distinguishable dimensions of soil-climate variables influencing the two leaf traits $\left(N_{\text {area }}\right.$ and $\left.g_{s}\right)$ that, together, largely constrain photosynthetic activity. Soil pH and available P emerged as the best soil predictors of variation along these gradients and, indeed, overall we found stronger patterning of photosynthetic traits according to unique effects of soils than to those of climate. Plant geographers have long recognized that plant traits vary in concert with soil properties (e.g. Schimper, 1903), but only rarely have such patterns been quantified at a broad spatial scale. This work represents an important step towards a better understanding of geographic variation in leaf photosynthetic strategies, and to progress towards more reliable modelling of global vegetation function.

\section{ACKNOWLEDGEMENTS}

We thank the many data contributors, including Claudia Keitel, Fernando Valladares and Margaret Barbour; Allyson Eller, Sean Gleason, Pedro Peres-Neto, Mark Westoby and the Wright lab for stimulating discussions; and Bjorn Reu and one anonymous referee who challenged us to clarify our analytical approach. The research was supported by ARC grants DP120103600 to I.C.P. and I.J.W. and FT100100910 to I.J.W., and by funding from Macquarie University. This paper is a contribution to the AXA Chair Programme in Biosphere and Climate Impacts and the Imperial College initiative on Grand Challenges in Ecosystems and the Environment.

\section{REFERENCES}

Batjes, N.H. (2011a) Overview of soil phosphorus data from a large international soil database. ISRIC Report 2011/01. Plant Research International (PRI), Wageningen UR, and ISRIC World Soil Information, Wageningen. Available at: http:// www.isric.org.

Batjes, N.H. (2011b) Global distribution of soil phosphorus retention potential. ISRIC Report 2011/06 Plant Research International (PRI), Wageningen UR, and ISRIC - World Soil Information, Wageningen. Available at: http://www.isric.org.

Batjes, N.H. (2012) ISRIC-WISE derived soil properties on a 5 by 5 arc-minutes global grid (ver. 1.2). ISRIC Report 2012/01. ISRIC - World Soil Information, Wageningen. Available at: http://www.isric.org.

Bray, R.H. \& Kurtz, L.T. (1945) Determination of total, organic, and available forms of phosphorus in soils. Soil Science, 59, 39-45. 
Cramer, M., Hawkins, H.-J. \& Verboom, G. (2009) The importance of nutritional regulation of plant water flux. Oecologia, 161, 15-24.

Edwards, D., Kerp, H. \& Hass, H. (1998) Stomata in early land plants: an anatomical and ecophysiological approach. Journal of Experimental Botany, 49, 255-278.

FAO (2004) Global map of monthly reference evapotranspiration - 10 arc minutes. FAO, Rome. Available at: http://www.fao.org/ geonetwork/srv/en/main.home.

FAO, IIASA, ISRIC, ISSCAS \& JRC (2012) Harmonized World Soil Database (version 1.2). FAO, Rome and IIASA, Laxenburg, Austria. Available at: http://webarchive.iiasa.ac.at/.

Farquhar, G.D., Buckley, T.N. \& Miller, J.M. (2002) Optimal stomatal control in relation to leaf area and nitrogen content. Silva Fennica, 36, 625-637.

Field, C., Merino, J. \& Mooney, H.A. (1983) Compromises between water use efficiency and nitrogen use efficiency in 5 species of California evergreens. Oecologia, 60, 384-389.

Fontaine, S., Hénault, C., Aamor, A., Bdioui, N., Bloor, J., Maire, V., Mary, B., Revaillot-Saccomano, S. \& Maron, P.-A. (2011) Fungi mediate long term sequestration of carbon and nitrogen in soil through their priming effect. Soil Biology and Biochemistry, 43, 86-96.

Givnish, T.J. (1986) On the economy of plant form and function: Proceedings of the Sixth Maria Moors Cabot Symposium. Cambridge University Press, Cambridge.

Hakkenberg, R., Churkina, G., Rodeghiero, M., Börner, A., Steinhof, A. \& Cescatti, A. (2008) Temperature sensitivity of the turnover times of soil organic matter in forests. Ecological Applications, 18, 119-131.

Han, W.X., Fang, J.Y., Reich, P.B., Ian Woodward, F. \& Wang, Z.H. (2011) Biogeography and variability of eleven mineral elements in plant leaves across gradients of climate, soil and plant functional type in China: biogeography and variability of leaf chemistry. Ecology Letters, 14, 788-796.

Hengl, T., Mendes De Jesus, J., Macmillan, R.A., Batjes, N.H., Heuvelink, G.B.M., Ribeiro, E.C., Samuel-Rosa, A., Kempen, B., Leenaars, J.G.B., Walsh, M.G. \& Gonzalez, M.R. (2014) SoilGrids $1 \mathrm{~km}$ - global soil information based on automated mapping. PLoS ONE, 9, 8, e105992.

Huston, M.A. (2012) Precipitation, soils, NPP, and biodiversity: resurrection of Albrecht's curve. Ecological Monographs, 82, 3, 277-296.

ISRIC (2013) SoilGrids: an automated system for global soil mapping, ISRIC - World Soil Information, Wageningen Available at: http://soilgrids1km.isric.org.

Jenny, H. (1941) Factors of soil formation: a system of quantitative pedology. Dover, New York.

Lambers, H., Raven, J., Shaver, G. \& Smith, S. (2008) Plant nutrient-acquisition strategies change with soil age. Trends in Ecology and Evolution, 23, 95-103.

Legendre, P. \& Legendre, L. (2012) Numerical ecology, 3rd Engl edn. Elsevier Science, Amsterdam.

Maire, V., Martre, P., Kattge, J., Gastal, F., Esser, G., Fontaine, S. \& Soussana, J.-F. (2012) The coordination of leaf photosyn- thesis links $\mathrm{C}$ and $\mathrm{N}$ fluxes in $\mathrm{C}_{3}$ plant species. PLoS ONE, 7, 6, e38345.

Medlyn, B.E., Duursma, R.A., Eamus, D., Ellsworth, D.S., Prentice, I.C., Barton, C.V.M., Crous, K.Y., De Angelis, P., Freeman, M. \& Wingate, L. (2011) Reconciling the optimal and empirical approaches to modelling stomatal conductance: reconciling optimal and empirical stomatal models. Global Change Biology, 17, 2134-2144.

Moles, A.T., Warton, D.I., Warman, L., Swenson, N.G., Laffan, S.W., Zanne, A.E., Pitman, A., Hemmings, F.A. \& Leishman, M.R. (2009) Global patterns in plant height. Journal of Ecology, 97, 923-932.

New, M., Lister, D., Hulme, M. \& Makin, I. (2002) A highresolution data set of surface climate over global land areas. Climate Research, 21, 1-25.

Niinemets, Ü., Tenhunen, J.D., Canta, N.R., Chaves, M.M., Faria, T., Pereira, J.S. \& Reynolds, J.F. (1999) Interactive effects of nitrogen and phosphorus on the acclimation potential of foliage photosynthetic properties of cork oak, Quercus suber, to elevated atmospheric $\mathrm{CO}_{2}$ concentrations. Global Change Biology, 5, 455-470.

Ordonez, A. \& Olff, H. (2013) Do alien plant species profit more from high resource supply than natives? A trait-based analysis. Global Ecology and Biogeography, 11, 6, 648-658.

Ordoñez, J.C., van Bodegom, P.M., Witte, J.-P.M., Wright, I.J., Reich, P.B. \& Aerts, R. (2009) A global study of relationships between leaf traits, climate and soil measures of nutrient fertility. Global Ecology and Biogeography, 18, 137-149.

Peltzer, D.A., Wardle, D.A., Allison, V.J., Baisden, W.T., Bardgett, R.D., Chadwick, O.A., Condron, L.M., Parfitt, R.L., Porder, S., Richardson, S.J., Turner, B.L., Vitousek, P.M., Walker, J. \& Walker, L.R. (2010) Understanding ecosystem retrogression. Ecological Monographs, 80, 509-529.

Poorter, H., Niklas, K.J., Reich, P.B., Oleksyn, J., Poot, P. \& Mommer, L. (2012) Biomass allocation to leaves, stems and roots: meta-analyses of interspecific variation and environmental control. New Phytologist, 193, 30-50.

Prentice, I.C., Dong, N., Gleason, S.M., Maire, V. \& Wright, I.J. (2014) Balancing the costs of carbon gain and water transport: testing a new theoretical framework for plant functional ecology. Ecology Letters, 17, 82-91.

Quesada, C.A., Lloyd, J., Schwarz, M. et al. (2010) Variations in chemical and physical properties of Amazon forest soils in relation to their genesis. Biogeosciences, 7, 1515-1541.

R Core Team (2013) R: a language and environment for statistical computing. R Foundation for Statistical Computing, Vienna, Austria.Available at: http://www.R-project.org/.

Raven, J.A., Handley, L.L. \& Wollenweber, B. (2004) Plant nutrition and water use efficiency. Water use efficiency in plant biology (ed. by M.A. Bacon), pp. 171-197. CRC Press, Boca Raton, FL.

Reich, P.B. (2014) The world-wide 'fast-slow' plant economics spectrum: a traits manifesto. Journal of Ecology, 102, 275-301.

Reich, P.B. \& Oleksyn, J. (2004) Global patterns of plant leaf N and $\mathrm{P}$ in relation to temperature and latitude. Proceedings of the National Academy of Sciences USA, 101, 11001-11006. 
Reich, P.B., Oleksyn, J. \& Wright, I.J. (2009) Leaf phosphorus influences the photosynthesis-nitrogen relation: a crossbiome analysis of 314 species. Oecologia, 160, 207-212.

Santiago, L.S., Schuur, E.A.G. \& Silvera, K. (2005) Nutrient cycling and plant-soil feedbacks along a precipitation gradient in lowland Panama. Journal of Tropical Ecology, 21, 461470.

Schimper, A.F.W. (1903) Plant geography upon a physiological basis. Clarendon Press, Oxford.

Schulze, E.-D., Williams, R.J., Farquhar, G.D., Schulze, W., Langridge, J., Miller, J.M. \& Walker, B.H. (1998) Carbon and nitrogen isotope discrimination and nitrogen nutrition of trees along a rainfall gradient in northern Australia. Australian Journal of Plant Physiology, 25, 413-425.

Shangguan, W., Dai, Y., Liu, B. et al. (2013) A China data set of soil properties for land surface modelling. Journal of Advances in Modeling Earth Systems, 5, 212-224.

Sinsabaugh, R.L. \& Follstad Shah, J.J. (2012) Ecoenzymatic stoichiometry and ecological theory. Annual Review of Ecology, Evolution, and Systematics, 43, 313-343.

Tóth, G., Jones, A. \& Montanarella, L. (2013) The LUCAS topsoil database and derived information on the regional variability of cropland topsoil properties in the European Union. Environmental Monitoring and Assessment, 185, 7409-7425.

Vitousek, P.M. (2004) Nutrient cycling and limitation. Hawaii as a model system. Princeton University Press, Princeton, NJ.

Walker, T.W. \& Syers, J.K. (1976) The fate of phosphorus during pedogenesis. Geoderma, 15, 1-19.

Wang, H., Prentice, I.C. \& Davis, T.W. (2014) Biophysical constraints on gross primary production by the terrestrial biosphere. Biogeosciences, 11, 5987-6001.

Westoby, M. \& Wright, I.J. (2006) Land-plant ecology on the basis of functional traits. Trends in Ecology and Evolution, 21, 261-268.

Wright, I.J., Reich, P.B. \& Westoby, M. (2001) Strategy-shifts in leaf physiology, structure and nutrient content between species of high and low rainfall, and high and low nutrient habitats. Functional Ecology, 15, 423-434.

Wright, I.J., Reich, P.B. \& Westoby, M. (2003) Least-cost input mixtures of water and nitrogen for photosynthesis. The American Naturalist, 161, 98-111.

Wright, I.J., Reich, P.B., Westoby, M. et al. (2004) The worldwide leaf economics spectrum. Nature, 428, 821-827.
Yemefacka, M., Rossiter, D.G. \& Njomgang, R. (2005) Multiscale characterization of soil variability within an agricultural landscape mosaic system in southern Cameroon. Geoderma, 125, 117-143.

\section{SUPPORTING INFORMATION}

Additional supporting information may be found in the online version of this article at the publisher's web-site.

Appendix S1 Literature used to extend the GLOPNET database.

Appendix S2 Dataset.

Appendix S3 Details on soil and climate variables and their biogeographic representation.

Appendix S4 Details on soil available phosphorus data.

Appendix S5 Discussion on the quality of soil and climate data. Appendix S6 Details on data analysis

Appendix S7 Details on soil-soil, climate-climate and soilclimate analyses.

Appendix S8 Details on plant traits - environment analyses.

\section{DATA ACCESSIBILITY}

Additional references to the data sources used in this study can be found in Appendices S1 \& S2 at the DRYAD Digital Repository (http://datadryad.org/) with the following doi address:10.5061/dryad.j42m7.

\section{BIOSKETCHES}

This research team aims to develop a better understanding of trait-environment interactions, particularly for use in 'next-generation' vegetation models based on plant functional traits. Expertise within the team extends from plant ecology to physiology to soil science and ecological theory.

Author contributions: V.M., I.J.W. and I.C.P. conceived the ideas and drafted the article; I.J.W. assembled the dataset with help from A.O. and V.M. V.M. performed the analyses. All authors contributed to the writing.

Editor: Greg Jordan 